\title{
A PCM-WATER HEAT EXCHANGER WITH POLYMERIC HOLLOW FIBRES FOR LATENT HEAT THERMAL ENERGY STORAGE: A PARAMETRIC STUDY OF DISCHARGING STAGE
}

\author{
Jiří HejČík, Pavel Charvát, Lubomír Klimeš \\ Brno University of Technology, Department of Thermodynamics and Environmental Engineering, Brno, Czech Republic \\ e-mail: hejcik@fme.vutbr.cz; charvat@fme.vutbr.cz; klimes@fme.vutbr.cz
}

ILYA Astrouski

Brno University of Technology, Heat Transfer and Fluid Flow Laboratory, Brno, Czech Republic

e-mail: astrouski@fme.vutbr.cz

\begin{abstract}
The paper presents a theoretical parametric study into latent heat thermal energy storage (LHTES) employing polymeric hollow fibres embedded in a phase change material (PCM). The polymeric hollow fibres of five inner diameters between $0.5 \mathrm{~mm}$ and $1.5 \mathrm{~mm}$ are considered in the study. The effectiveness-NTU method is employed to calculate the thermal performance of a theoretical LHTES unit of the shell-and-tube design. The results indicate that the hollow fibres embedded in a PCM can mitigate the drawback of low thermal conductivity of phase change materials. For the same packing fraction, the total heat transfer rates between the heat transfer fluid and the PCM increase with the decreasing diameter of the hollow fibres. This increase in the heat transfer rate and thus the efficiency of the heat exchange to some extent compensate for the energy consumption of the pump that also increases with the decreasing fibre diameter.
\end{abstract}

Keywords: polymeric hollow fibre, heat exchanger, latent heat thermal energy storage, phase change materials

\section{Introduction}

The polymeric hollow fibre heat exchanger (PHFHE) is a relatively novel type of heat exchanger that employs thin-wall polymeric fibres for separation of heat transfer fluids. The hollow fibres can be produced by the extrusion process from a variety of polymers such as polypropylene $(\mathrm{PP})$, polyethylene (PE), polyether ether ketone (PEEK) as well as from certain polymers with increased conductivity. The PHFHEs are an alternative to conventional metal heat exchangers for low temperature applications (Zarkadas and Sirkar, 2004).

A number of heat transfer devices was constructed and tested for both liquid and gaseous heat transfer fluids. One of the most common designs of a PHFHE is the one similar to the shell-and-tube heat exchanger. The PHFHEs have rather high ratios between the heat transfer area and the volume (around $1400 \mathrm{~m}^{2} / \mathrm{m}^{3}$ ). Zarkadas and Sirkar (2004) reported the overall heat transfer coefficients of these devices between $647 \mathrm{~W} / \mathrm{m}^{2} \mathrm{~K}$ and $1314 \mathrm{~W} / \mathrm{m}^{2} \mathrm{~K}$ for water-to-water heat transfer application. It was shown that the overall conductance per unit of volume of the PHFHE (around $1.2 \cdot 10^{6} \mathrm{~W} / \mathrm{m}^{3} \mathrm{~K}$ ) is larger than in the case of conventional metallic shell-and-tube exchangers and slightly less than in the case of the plate heat exchangers. Song et al. (2010) presented a lab study aimed at the use PHFHEs in the thermal desalination process. The metallic heat exchangers suffer from corrosive behaviour of salt water while the plastics withstand salt water quite well. The two experimental lab-scale PHFHEs were of the shell-and-tube design and contained solid polypropylene hollow fibres (950 and 2750, respectively) with 
the outer diameter of $0.58 \mathrm{~mm}$ and the wall thickness of $0.075 \mathrm{~mm}$. The experimental PHFHEs had large values of packing fraction (0.59 and 0.63, respectively) and the surface area/volume ratios of $3061 \mathrm{~m}^{2} / \mathrm{m}^{3}$ and $3290 \mathrm{~m}^{2} / \mathrm{m}^{3}$, respectively. The heat transfer performance of the PHFHEs was studied for a hot brine $\left(80^{\circ} \mathrm{C}\right.$ to $\left.98^{\circ} \mathrm{C}\right)$ - cold water $\left(8^{\circ} \mathrm{C}\right.$ to $\left.25^{\circ} \mathrm{C}\right)$ system as well as for a steam $\left(101^{\circ} \mathrm{C}\right.$ to $\left.113^{\circ} \mathrm{C}\right)$ - cold water $\left(8^{\circ} \mathrm{C}\right.$ to $\left.25^{\circ} \mathrm{C}\right)$ system as these systems are typically encountered in thermal desalination plants. The overall heat transfer coefficient as high as $2000 \mathrm{~W} / \mathrm{m}^{2} \mathrm{~K}$ was achieved, which was close to the limiting value imposed by the PP wall thickness $\left(2660 \mathrm{~W} / \mathrm{m}^{2} \mathrm{~K}\right)$. The overall conductance per unit of volume was around $6.1 \cdot 10^{5}-3.5 \cdot 10^{6} \mathrm{~W} / \mathrm{m}^{3} \mathrm{~K}$, which is higher than that of metallic shell-and-tube heat exchangers and comparable with the best plate heat exchangers.

The present paper deals with a theoretical study aimed at application of PHFHEs in the latent heat thermal energy storage. The polymeric hollow fibres embedded in a phase change material (PCM) represent a way to increase the heat transfer rates between the heat transfer fluid (HTF) and the PCM. The analysis has been performed for a PCM-water latent heat thermal energy storage (LHTES) unit of the shell-and-tube design where the tubes are polymeric hollow fibres and the shell is filled with a PCM.

\section{Fluid flow and heat transfer in polymeric hollow fibres}

The polymeric hollow fibres have the inner diameter of around $10^{-3} \mathrm{~m}$. Therefore, the fluid flow and heat transfer in hollow fibres is essentially the fluid flow and heat transfer in minichannels as classified by Kandlikar and Grande (2003) where the minichannels were channels with diameter between $200 \mu \mathrm{m}$ and $3 \mathrm{~mm}$. The fluid flow in minichannels is characterized by low Reynolds numbers. A number of correlations for minichannels and microchannels can be found in Tullius et al. (2012). It has been shown that the fluid flow and heat transfer in minichannels is in a good agreement with the criteria established for channels of much larger diameters (Herwig and Hausner, 2003; Celata et al., 2006; Dutkowski, 2008). A significant deviation could occur in microchannels of very small diameters - only a few micrometers. Such channel diameters are close to the free mean path of the molecules where the assumption of continuum in the case of fluid flow no longer applies. However, the polymeric hollow fibres used in the PHFHEs do not have the inner diameter of less than $0.1 \mathrm{~mm}(100 \mu \mathrm{m})$ and the assumption of the continuum for heat and mass transfer is valid. Also, the decreasing diameter of a channel translates into increasing pressure drop. Since the pressure drop significantly influences operating costs of heat exchangers, the fluid velocities in the polymeric hollow fibres need to be rather small to achieve reasonable pressure drops. Figure 1 shows the pressure drop of 1 meter length of the hollow fibres

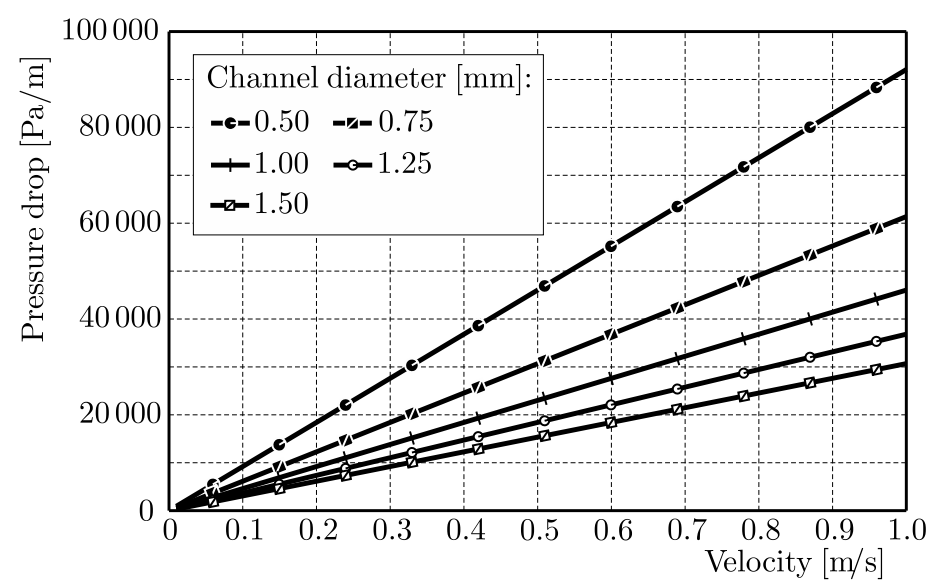

Fig. 1. Pressure drop as a function of the channel diameter and water velocity 
of five inner diameters between $0.5 \mathrm{~mm}$ and $1.5 \mathrm{~mm}$. The Reynolds number for all the cases was Re $\leqslant 2000$, which means laminar flow. The Nusselt number in the case of the laminar flow only depends on the boundary condition; a constant heat flux or a constant wall temperature. The Nusselt number is defined as $\mathrm{Nu}=h d / k$ where $h$ is the heat transfer coefficient, $d$ is the inner diameter and $k$ is the thermal conductivity of the fluid. The Nusselt number for laminar flow in a circular channel is $\mathrm{Nu}=4.36$ for the constant heat flux through the wall of the channel and $\mathrm{Nu}=3.66$ for constant wall temperature (Incropera et al., 2006). It can be concluded from the definition of the Nusselt number that the heat transfer coefficient increases rapidly for channel diameters below $1 \mathrm{~mm}$ (microchannels). However, it is important to not overestimate the influence of heat transfer coefficient on the overall heat transfer rates.

\section{Hollow fibres embedded in phase change materials}

The phase change materials (PCMs) as the media for LHTES have received a lot of attention in the last two decades (Oró et al., 2012; Sharma et al., 2009; Zalba et al., 2003). In contrast to sensible heat storage, the phase change of a material offers a relatively high thermal storage capacity and energy storage density in a narrow temperature interval around the temperature of the phase change. Nonetheless, the practical application of the PCMs in LHTES is still relatively limited. One of the reasons is rather low thermal conductivity of most PCMs (Jegadheeswaran and Pohekar, 2009). Many possibilities to increase the heat transfer rates between the heat transfer fluid (HTF) and the PCM have been proposed; from extended heat transfer surfaces (Al-Abidi et al., 2014; Kozak et al., 2014) to metal foams (Zhao et al., 2010) and to nanoparticles (Raam Dheep and Sreekumar, 2014). This paper discusses the potential use of polymeric hollow fibres embedded in a PCM as a way to increase the heat transfer rates between the PCM and the heat transfer fluid. Five inner diameters of hollow fibres are considered: $0.5 \mathrm{~mm}, 0.75 \mathrm{~mm}$, $1 \mathrm{~mm}, 1.25 \mathrm{~mm}$ and $1.5 \mathrm{~mm}$. The wall thickness of the fibres is proposed in a way to achieve the same hoop stress in the wall of the fibre for the same HTF pressure. This assumption leads to a constant ratio between the outer and the inner diameter of the fibre and consequently to the same value of the thermal resistance of heat conduction through the fibre wall (per unit of length).

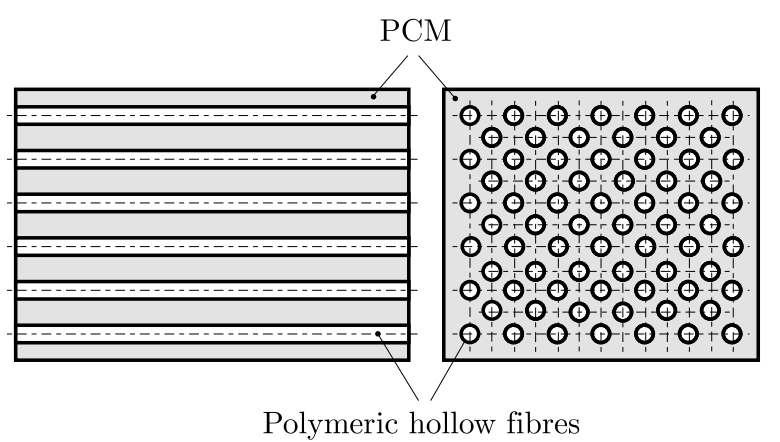

Fig. 2. Polymeric hollow fibres embedded in the PCM

Figure 2 shows a schematic view of polymeric hollow fibres embedded in a phase change material. The theoretical analysis presented in this paper focuses on the thermal performance of such an arrangement in thermal energy storage. The hexagonal pattern of the hollow fibres was considered as shown in Fig. 3. In this pattern, the distance between any two adjacent hollow fibres is the same since the distances of the fibres are the sides of equilateral triangles. The distance of the fibres, called the pitch and marked $P_{T}$ in Fig. 3, is usually expressed in relation to the diameter of the tube (polymeric hollow fibre in this case). The ratio between the pitch $P_{T}$ 
and the outer fibre diameter $D$ in the design of the conventional fluid-to-fluid shell-and-tube heat exchangers is between 1.25 and 1.5. This is equivalent to the packing fraction (the ratio of the tube bundle cross section area to the shell cross section area) between 0.58 (for $P_{T} / D=1.25$ ) and 0.4 (for $P_{T} / D=1.5$ ).

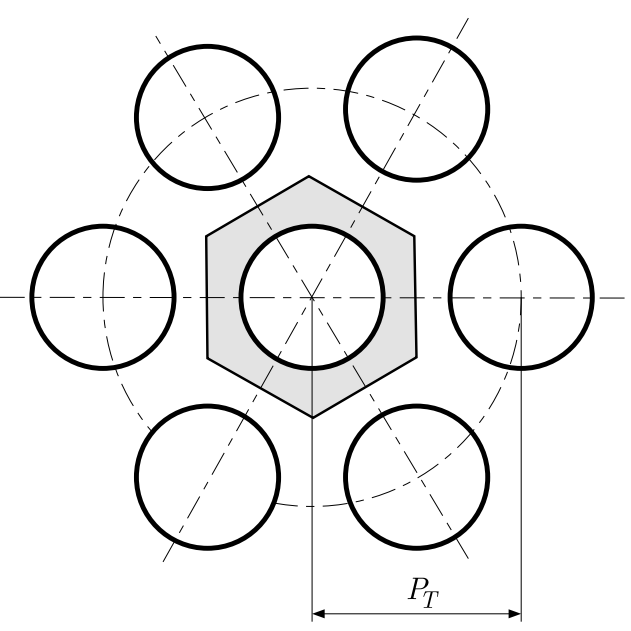

Fig. 3. Hexagonal arrangement of the fibres

Various combinations of the fibre inner diameter $d$ and the fibre pitch $P_{T}$ produce values of the heat exchanger area density between $548 \mathrm{~m}^{2} / \mathrm{m}^{3}$ and $2369 \mathrm{~m}^{2} / \mathrm{m}^{3}$, see Fig. 4 . The situation in Fig. 4 applies to fluid-to-fluid heat exhangers. It shows that it is possible to reach high thermal performance with a small volume of the heat exchanger with the use of hollow fibres, because a decrease in the fibre diameter leads to a simultaneous increase in the heat transfer coefficient and the area density. However, the largest value of area density is reached for the combination of the minimal fibre diameter and the smallest fibre pitch. Hence, a very small volume of the phase change material remains around the fibres. This significantly reduces the overall thermal storage capacity of LHTES units with this design. Therefore, the packing fraction of the shell-and-tube LHTES units with PCMs needs to be much smaller than in the case of the shell-and-tube heat exchangers for fluid-to-fluid heat transfer. In the present study, the ratio $P_{T} / D=10$ that provides much larger volume and thus overall thermal capacity of the PCM is used. In general, the smaller the $P_{T} / D$ ratio the higher overall heat transfer rates between the PCM and the heat transfer fluid can be achieved. An optimal $P_{T} / D$ ratio would depend on the purpose and operating conditions of the LHTES unit.

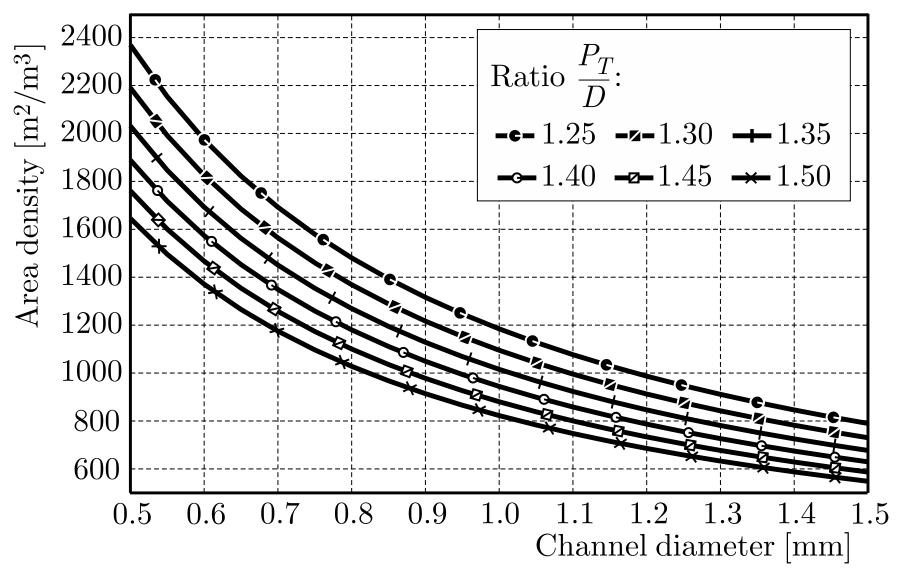

Fig. 4. Area density for different fibre diameters and $P_{T} / D$ ratios 
The presented parametric study takes into account both the heat transfer in the hollow fibres and the amount of stored energy. Several assumptions and simplifications have been adopted in the study. The phase change of the PCM is considered isothermal (taking place at constant temperature). This assumption has frequently been adopted by other authors, e.g. Aadmi et al. (2015), Hu and Patniak (2014), Zivkovic and Fuji (2001). The amount of the heat storage material belonging to one hollow fibre has been calculated from the hexagonal section (grey area in Fig. 3) and the length of the fibre. The thickness of the melted/solidified layer of the PCM along the length of the fibre is considered to be constant. The analysis of the thermal behaviour of hollow fibres in the LHTES unit has been based on the $\varepsilon$-NTU methodology (Tay et al., 2012) where the thermal performance characteristics of a heat exchanger are described by the equations

$$
\varepsilon=1-\mathrm{e}^{-\mathrm{NTU}} \quad \mathrm{NTU}=\ln \left(\frac{1}{1-\varepsilon}\right)
$$

where $\varepsilon$ is the heat exchanger effectiveness and NTU is the Number of Transfer Units. Since the phase change occurs at a constant temperature $T_{m e l t}$, the medium with minimal heat capacity rate $C_{\min }$ is the heat transfer fluid. The heat exchanger effectiveness thus represents the efficiency of charging (or discharging) of heat by means of the HTF, and it can be expressed by the following equation

$$
\varepsilon=\frac{T_{\text {in }}-T_{\text {out }}}{T_{\text {in }}-T_{\text {melt }}}
$$

where $T_{\text {in }}$ is the HTF inlet temperature, $T_{\text {out }}$ is the HTF outlet temperature and $T_{\text {melt }}$ is PCM melting temperature. The heat transfer rate used for charging/discharging is calculated from the parameter NTU, which is defined as

$$
\mathrm{NTU}=\frac{U A}{C_{\min }}
$$

where $U$ is the overall heat transfer coefficient, $A$ is the heat transfer area and $C_{m i n}$ is the minimal heat capacity rate, which is the product of mass flow rate $\dot{m}_{\mathrm{HTF}}$ and the specific heat $c_{\mathrm{HTF}}$ of the $\mathrm{HTF}, C_{\min }=\dot{m}_{\mathrm{HTF}} c_{\mathrm{HTF}}$.

The $U A$ parameter is derived from the thermal storage geometry and the physical properties of the HTF and it is equal to the inverted value of the overall thermal resistance. Three thermal resistances are taken into account in the parametric study. The first one is the convective thermal resistance inside the hollow fibre, based on the heat transfer coefficient for the fully developed laminar flow with the constant wall temperature $(\mathrm{Nu}=3.66)$. The second thermal resistance is the conductive resistance of the fibre wall. Finally, the third resistance is the heat transfer resistance through the solid PCM material which built up around the fibre surface during the discharge of heat from thermal energy storage. The resistance of the melted PCM around the fibre surface would be used in the case of charging of the thermal storage. The thermal resistance of the melting/solidification front is neglected and the $U A$ value has been calculated using following equation

$$
\frac{1}{U A}=\sum_{i} R_{i}=\frac{1}{h_{i n} \pi d L}+\frac{\ln \frac{D}{d}}{2 \pi k_{w} L}+\frac{\ln \frac{D_{\mathrm{PCM}}}{D}}{2 \pi k_{\mathrm{PCM}} L}
$$

where $h_{i n}$ is the heat transfer coefficient inside the fibre, $d$ is the inner diameter of the hollow fibre, $L$ is the fibre length, $D$ is the fibre outer diameter, $k_{w}$ is the thermal conductivity of the fibre wall, $D_{\mathrm{PCM}}$ is the diameter on which the melting/solidification front is located and $k_{\mathrm{PCM}}$ is the thermal conductivity of the solid PCM surrounding the fibre. 


\section{Results and discussion}

Quasi-steady-state thermal calculations have been carried out for comparison of several hollow fibre diameters in the LHTES unit. The heat loss to the ambient environment is neglected as is a common assumption in theoretical studies (Belusko et al., 2012; Pinnau and Breitkopf, 2015; Daugenet-Frick et al., 2015). The study focuses on heat transfer between the HTF and the PCM and not on the overall thermal performance of an actual LHTES unit, so it has been justifiable to assume an adiabatic shell of the unit. Nevertheless, it needs to be emphasized that the heat loss to the ambient environment can significantly influence the real-life operation of LHTES units. The internal volume of the LHTES unit is considered $1 \mathrm{~m}^{3}$ and the PHFHE consisted of $1 \mathrm{~m}$ long fibres that are assembled in the hexagonal pattern (Fig. 3) with the pitch $P_{T} / D=10$. Therefore, the packing fraction is the same for all fibre diameters and the LHTES unit contains the same weight of PCM in all studied cases. The calculations start with the LHTES unit containing the liquid PCM at the melting temperature. The heat stored in the unit is discharged by water flowing through the hollow fibres (the water flow rate was $60 \ell / \mathrm{min}$ ). The initial condition is $D_{\mathrm{PCM}}=D$ at the time $t=0$, which means the PCM thermal resistance is equal to zero. The calculations have been performed with the time step $\Delta t=30 \mathrm{~s}$. The input data for calculations and the considered parameters of the LHTES unit are presented in Tables 1 and 2.

Table 1. LHTES unit parameters

\begin{tabular}{|l|c|c|c|c|c|}
\hline \multirow{2}{*}{ Parameter } & \multicolumn{5}{|c|}{ Simulation } \\
\cline { 2 - 6 } & 1 & 2 & 3 & 4 & 5 \\
\hline \hline$d$ & $0.5 \mathrm{~mm}$ & $0.75 \mathrm{~mm}$ & $1 \mathrm{~mm}$ & $1.25 \mathrm{~mm}$ & $1.5 \mathrm{~mm}$ \\
$D$ & $0.7 \mathrm{~mm}$ & $1.05 \mathrm{~mm}$ & $1.4 \mathrm{~mm}$ & $1.75 \mathrm{~mm}$ & $2.1 \mathrm{~mm}$ \\
$P_{T}$ & $7 \mathrm{~mm}$ & $10.5 \mathrm{~mm}$ & $14 \mathrm{~mm}$ & $17.5 \mathrm{~mm}$ & $21 \mathrm{~mm}$ \\
Number of fibres & 23565 & 10473 & 5891 & 3770 & 2618 \\
\hline
\end{tabular}

Table 2. Calculation inputs and parameters

\begin{tabular}{|c|c|}
\hline \multicolumn{2}{|l|}{ PCM properties } \\
\hline Melting temperature $T_{\text {melt }}$ & $30^{\circ} \mathrm{C}$ \\
\hline Latent heat & 200 kJ/kg \\
\hline Density & $760 \mathrm{~kg} / \mathrm{m}^{3}$ \\
\hline Thermal conductivity (solid) $k_{\mathrm{PCM}}$ & $0.2 \mathrm{~W} / \mathrm{mK}$ \\
\hline \multicolumn{2}{|l|}{ HTF - water } \\
\hline $\begin{array}{l}\text { Inlet temperature } T_{i n} \\
\text { Flow rate } \dot{m}_{\mathrm{HTF}}\end{array}$ & $\begin{array}{c}25^{\circ} \mathrm{C} \\
60 \ell / \min \end{array}$ \\
\hline \multicolumn{2}{|l|}{ Fibre material } \\
\hline Thermal conductivity & $0.18 \mathrm{~W} / \mathrm{mK}$ \\
\hline Volume & $1 \mathrm{~m}^{3}$ \\
\hline Amount of PCM & $753 \mathrm{~kg}$ \\
\hline Latent heat capacity & $1.5 \mathrm{GJ}$ \\
\hline Packing fraction & 0.009 \\
\hline
\end{tabular}

Figure 5 shows the time needed to discharge heat from the LHTES unit in the case of five hollow fibre diameters. It is evident that the LHTES unit with the small diameter fibres is more efficient as it takes less time to solidify all the PCM. This corresponds with the results presented in Fig. 6 that shows the heat exchanger efficiency as a function of the solid fraction. The heat transfer efficiency of the small diameter fibres remains high during the entire heat 


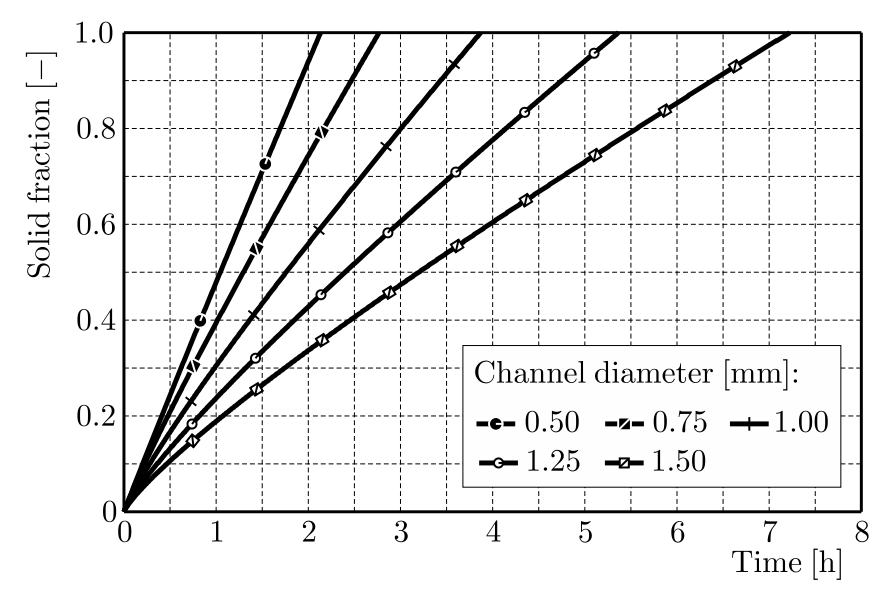

Fig. 5. Time vs. solid fraction for different fibre diameters

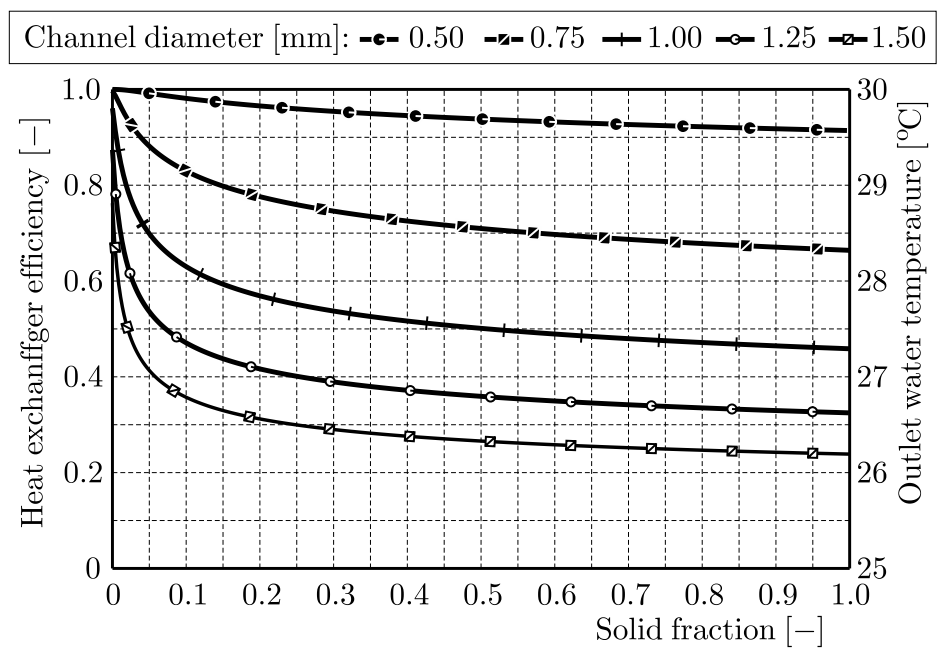

Fig. 6. Heat exchanger efficiency and outlet water temperature as functions of the solid fraction

discharge process. It is the result of very high heat transfer area of the hollow fibres with the small diameter which are surrounded by quite a thin layer of the PCM.

The efficiency of the heat exchanger influences the outlet temperature of the water as can be seen in Eq. (3.2). Even when the solidification of the PCM takes place at a constant temperature, as assumed in this study, the outlet water temperature changes during the heat discharge process, see Fig. 6. This fact can have significant consequences for real-life operation of LHTES. One of the advantages of LHTES is that heat is stored and released in a narrow temperature interval around the melting point of the heat storage medium (PCM). If there is a certain requirement on the minimum outlet temperature of the HTF, the total thermal storage capacity of a LHTES unit may not be utilized as the HTF outlet temperature drops below the required value during discharge of heat.

A high efficiency of the heat exchanger with small diameter fibres is countered by a higher pressure drop. The pressure drop in the case of $0.5 \mathrm{~mm}$ hollow fibres is almost 9 times higher than that in the case of $1.5 \mathrm{~mm}$ fibres. This translates into an increase in the pump power for the same water flow rates and the same packing fraction. Figure 7 shows the pump power as a function of the flow rate for the considered LHTES unit. The pump power has been obtained as

$$
P_{p}=\frac{\dot{V} \Delta p}{\eta}
$$




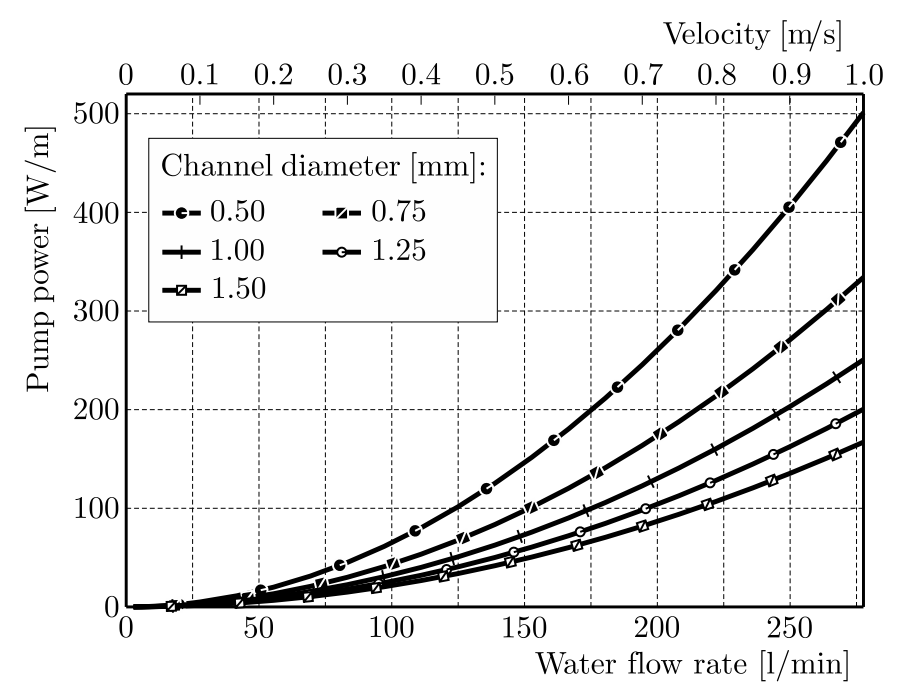

Fig. 7. Pump power as a function of the water flow rate

where $\dot{V}$ is the volumetric flow rate, $\Delta p$ is the pressure drop and $\eta$ is the efficiency of the pump. For the sake of comparison, a constant efficiency of the pump $\eta=0.85$ is considered in all cases. Though the required pump power increases with the decreasing inner diameter of the fibre. A better efficiency of the heat exchangers with small diameters of the fibres reduces the overall energy consumed by the pump during a heat storage cycle. As can be seen in Fig. 5, the time needed to discharge the heat from the heat storage unit is much shorter in the case of $0.5 \mathrm{~mm}$ fibres than in the case of $1.5 \mathrm{~mm}$ fibres.

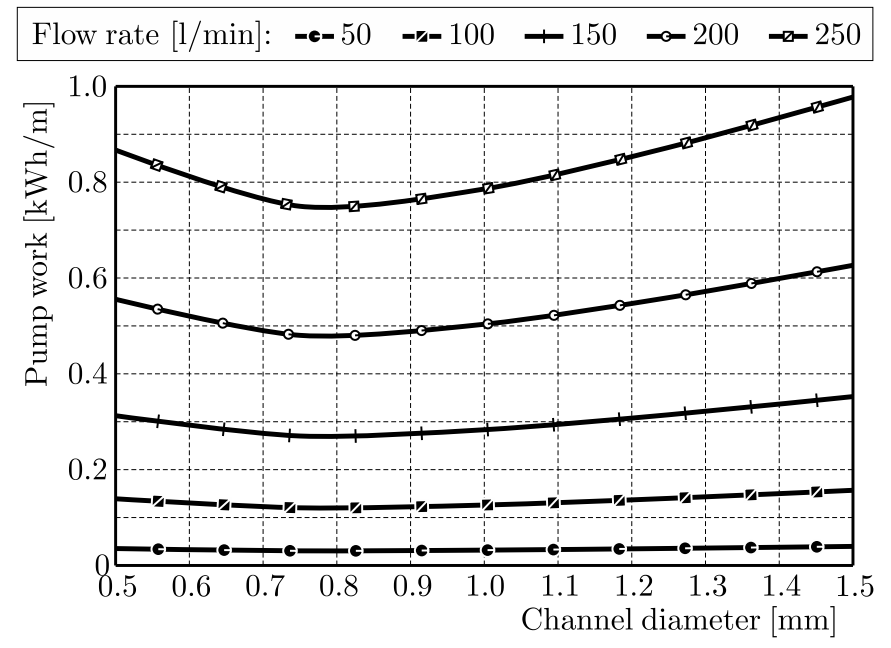

Fig. 8. Pump power as a function of the channel diameter

Figure 8 shows the energy consumed by a pump during the heat discharge period. The energy is obtained as

$$
E=\int_{0}^{t} P_{p} d t
$$

where $t$ is the time needed for the discharge of the heat from the LHTES unit and $P_{p}$ is the pump power given by Eq. (4.1). As can be seen in Fig. 8, the curves of energy consumption have a minimum for certain diameters of the hollow fibres. A parameter similar to COP can be defined as a ratio between the amount of heat charged into and/or discharged from the LHTES unit 
and the energy consumed by the pump. Such a parameter can then be used in multi-criterion optimization of the design of the LHTES units with polymeric hollow fibres.

The presented parametric study is relatively simple but it shows the potential of the polymeric hollow fibre heat exchangers in the latent heat thermal energy storage. There are many obstacles to overcome in design and manufacturing of such units, e.g. LHTES units containing tens of thousands of hollow fibres would be both difficult and costly to produce. For these reasons, the small units for short-term thermal energy storage with high heat storage and heat release rates seem to be a more promising area of application of PHFHE than the large-scale thermal energy storage. One area of application could be automotive industry where various ways of LHTES have been studied in the last several years (Kim et al., 2010; Javani et al., 2014; Kauranen et al., 2010).

\section{Conclusions}

The polymeric hollow fibre heat exchangers (PHFHEs) provide a large surface area density that can compensate for the small thermal conductivity of phase change materials (PCMs) in the latent heat thermal energy storage (LHTES). Moreover, PHFHEs are resistant to corrosive behaviour of some PCMs and heat transfer fluids. The results of the conducted parametric study are in line with the expectations and they indicate strengths and weaknesses of the PHFHE in LHTES in terms of heat transfer between the heat transfer fluid and the PCM. The efficiency of the PHFHE in LHTES decreases with the increasing solid fraction of a PCM. For the constant mass of a PCM, constant length of the hollow fibres and constant packing fraction, the heat transfer rates and the efficiency increase with the decreasing diameter of the hollow fibres. An increase in the packing fraction leads to an increase in the heat transfer rates but at the expense of decreasing energy storage density. For a constant packing fraction, the diameter of the hollow fibre can be found that provides the maximum ratio between the stored heat and the pump energy.

\section{Acknowledgement}

The research leading to the presented results was supported by the Czech Science Foundation under contract number P101/11/P538 and GA15-19162S.

\section{References}

1. Aadmi M., Karkri M., El Hammouti M., 2015, Heat transfer characteristics of thermal energy storage for PCM (phase change material) melting in horizontal tube: Numerical and experimental investigations, Energy, 85, 339-352, DOI: 10.1016/j.energy.2015.03.085

2. Al-Abidi A.A., Mat S., Sopian K., Sulaiman M.Y., Mohammad A.T., 2014, Experimental study of melting and solidification of PCM in a triplex tube heat exchanger with fins, Energy and Buildings, 68, 33-41, DOI: 10.1016/j.enbuild.2013.09.007

3. Belusko M., Halawa E., Bruno F., 2012, Characterising PCM thermal storage systems using the effectiveness-NTU approach, International Journal of Heat and Mass Transfer, 55, 13/14, 3359-3365, DOI: 10.1016/j.ijheatmasstransfer.2012.03.018

4. Celata G.P., Cumo M., Marconi V., McPhail S.J., Zummo G., 2006, Microtube liquid single-phase heat transfer in laminar flow, International Journal of Heat and Mass Transfer, 49, 19/20, 3538-3546, DOI: 10.1016/j.ijheatmasstransfer.2006.03.004

5. Daguenet-Frick X., Gantenbein P., Frank E., Fumey B., Weber R., 2015, Development of a numerical model for the reaction zone design of an aqueous sodium hydroxide seasonal thermal energy storage, Solar Energy, 121, 17-30, DOI: 10.1016/j.solener.2015.06.009. 
6. Dutkowski K., 2008, Experimental investigations of Poiseuille number laminar flow of water and air in minichannels, International Journal of Heat and Mass Transfer, 51, 25/26, 5983-5990, DOI: 10.1016/j.ijheatmasstransfer.2008.04.070

7. Herwig H., Hausner O., 2003, Critical view on new results in micro-fluid mechanics: an example, International Journal of Heat and Mass Transfer, 46, 5, 935-937, DOI: 10.1016/S00179310(02)00306-X

8. Hu X., Patnaik S.S., 2014, Modeling phase change material in micro-foam under constant temperature condition, International Journal of Heat and Mass Transfer, 68, 677-682, DOI: 10.1016/j.ijheatmasstransfer.2013.09.054

9. Incropera F.P., DeWitt D.P., Bergman T.L., Lavine A.S., 2006, Fundamentals of Heat and Mass Transfer, Wiley, New York

10. Javani N., Dincer I., Naterer G.F., 2014, New latent heat storage system with nanoparticles for thermal management of electric vehicles, Journal of Power Sources, 268, 718-727, DOI: 10.1016/j.jpowsour.2014.06.107

11. Jegadheeswaran S., Pohekar S.D., 2009, Performance enhancement in latent heat thermal storage system: A review, Renewable and Sustainable Energy Reviews, 13, 9, 2225-2244, DOI: 10.1016/j.rser.2009.06.024

12. Kandlikar S.G., Grande W.J., 2003, Evolution of microchannel flow passages: thermohydraulic performance and fabrication technology, Heat Transfer Engineering, 24, 1, 3-17, DOI: $10.1080 / 01457630304040$

13. Kauranen P., Elonen T., Wikström L., Heikkinen J., Laurikko J., 2010, Temperature optimisation of a diesel engine using exhaust gas heat recovery and thermal energy storage (diesel engine with thermal energy storage), Applied Thermal Engineering, 30, 6/7, 631-638, DOI: 10.1016/j.applthermaleng.2009.11.008

14. Kim K., Choi K., Kim Y., Lee K., Lee K., 2010, Feasibility study on a novel cooling technique using a phase change material in an automotive engine, Energy, 35, 1, 478-484, DOI: 10.1016/j.energy.2009.10.015

15. Kozak Y., Rozenfeld T., Ziskind G., 2014, Close-contact melting in vertical annular enclosures with a non-isothermal base: Theoretical modeling and application to thermal storage, International Journal of Heat and Mass Transfer, 72, 114-127, DOI: 10.1016/j.ijheatmasstransfer.2013.12.058

16. Oró E., de Gracia A., Castell A., Farid M.M., Cabeza L.F., 2012, Review on phase change materials (PCMs) for cold thermal energy storage applications, Applied Energy, 99, 513-533, DOI: 10.1016/j.apenergy.2012.03.058

17. Pinnau S., Breitkopf C., 2015, Determination of thermal energy storage (TES) characteristics by Fourier analysis of heat load profiles, Energy Conversion and Management, 101, 343-351, DOI: 10.1016/j.enconman.2015.05.055

18. RaAm Dheep G., Sreekumar A., 2014, Influence of nanomaterials on properties of latent heat solar thermal energy storage materials - A review, Energy Conversion and Management, 83, 133-148, DOI: 10.1016/j.enconman.2014.03.058

19. Sharma A., Tyagi V.V., Chen C.R., Buddhi D., 2009, Review on thermal energy storage with phase change materials and applications, Renewable and Sustainable Energy Reviews, 13, 2, 318-345, DOI: 10.1016/j.rser.2007.10.005

20. Song L., Li B., Zarkadas D., Christian S., Sirkar K., 2010, Polymeric hollow-fiber heat exchangers for thermal desalination processes, Industrial and Engineering Chemistry Research, 49, 23, 11961-11977, DOI: 10.1021/ie100375b

21. Tay N.H.S., Belusko M., Bruno F., 2012, An effectiveness-NTU technique for characterising tube-in-tank phase change thermal energy storage systems, Applied Energy, 91, 1, 309-319, DOI: 10.1016/j.apenergy.2011.09.039 
22. Tullius J.F., Tullius T.K., Bayazitoglu Y., 2012, Optimization of short micro pin fins in minichannels, International Journal of Heat and Mass Transfer, 55, 15/16, 3921-3932, DOI: 10.1016/j.ijheatmasstransfer.2012.03.022

23. Zalba B., Marin J.M., Cabeza L.F., Mehling H., 2003, Review on thermal energy storage with phase change: materials, heat transfer analysis and applications, Applied Thermal Engineering, 23, 3, 251-283, DOI: 10.1016/S1359-4311(02)00192-8

24. Zarkadas D.M., Sirkar K.K., 2004, Polymeric hollow fiber heat exchangers: An alternative for lower temperature applications, Industrial and Engineering Chemistry Research, 43, 25, 8093-8106, DOI: $10.1021 / \mathrm{ie} 040143 \mathrm{k}$

25. Zhao C.Y., Lu W., Tian Y., 2010, Heat transfer enhancement for thermal energy storage using metal foams embedded within phase change materials (PCMs), Solar Energy, 84, 8, 1402-1412, DOI: $10.1016 /$ j.solener.2010.04.022

26. Zivkovic B., Fujir I., 2001, An analysis of isothermal phase change of phase change material within rectangular and cylindrical containers, Solar Energy, 70, 1, 51-61, DOI: 10.1016/S0038092X(00)00112-2 